\title{
Cow milk does not affect adiposity in growing piglets as a model for children
}

\author{
Katherine Swanson, Michelle Kutzler, and Massimo Bionaz* \\ Department of Animal and Rangeland Sciences, Oregon State University, Corvallis 97331
}

\begin{abstract}
The effect of milk consumption on childhood obesity is unclear and a direct demonstration of an association is needed. In the present study, we used piglets as a model for prepubertal children to determine the effect of milk on adipose tissue. Two studies were conducted: study 1 with 5 -wk-old male piglets $(\mathrm{n}=8)$ and study 2 with 8 - to 9 -wk-old male piglets $(\mathrm{n}=12)$. The piglets were fed a normal growing diet and randomly assigned to receive daily either $750 \mathrm{~mL}$ of whole cow milk or an isocaloric maltodextrin solution (control). For approximately $12 \mathrm{wk}$, body weight, feed intake, and subcutaneous back fat thickness were determined ultrasonographically and recorded. At euthanasia, back and neck fat thicknesses were measured and samples of back fat were collected for adipose histology. In study 1 , but not study 2, piglets receiving milk grew more and ate more compared with control. In study 1 , both back fat and neck fat thickness were greater in the milk-fed piglets and they had a higher frequency of small adipocytes and a lower frequency of intermediate and large adipocytes compared with controls. In study 2 , control pigs had a significantly greater frequency of intermediate adipocytes but the milk-fed piglets tended to have a higher frequency of the largest adipocytes. In conclusion, milk has no apparent causal or consistent effect on adipose tissue in growing piglets.

Key words: milk, obesity, piglets
\end{abstract}

\section{INTRODUCTION}

The prevalence of childhood obesity increased from $5 \%$ in 1971 to $17 \%$ in 2004 in children 2 to $19 \mathrm{yr}$ of age but has since plateaued for unknown reasons (Lakshman et al., 2012; Cheung et al., 2016). Despite the plateau, childhood obesity is a serious concern because

Received June 12, 2018.

Accepted February 3, 2019.

*Corresponding author: massimo.bionaz@oregonstate.edu it is a strong predictor of adult obesity, with one-third of adults being considered obese in the United States (Ogden et al., 2015). Obesity is commonly associated with many diseases, such as type 2 diabetes and metabolic syndrome (Papoutsi et al., 2013; Xu and Xue, 2016; Kim et al., 2017). There is much debate about the best ways to prevent and treat childhood obesity, with many different foods being presented as the best to avoid (Papoutsi et al., 2013). Although not supported by scientific data, dairy foods, including milk, have been portrayed by the media as unhealthy and increasing the risk of obesity because of their higher energy density and levels of saturated fat (Kratz et al., 2013). This has led to a decrease in milk consumption as well as a recommendation from the American Academy of Pediatrics that children should drink skim or $1 \%$ milk instead of $2 \%$ or whole milk, especially if there is a family history of obesity (Daniels and Greer, 2008; Ludwig and Willett, 2013).

More recently, studies have found a negative correlation between the consumption of whole milk and incidence of childhood obesity (Huh et al., 2010; Vanderhout et al., 2016). Several studies have also demonstrated that dairy fat is negatively associated with obesity in adults (Zemel, 2005). These studies indicated that dairy products, and especially fat from these products, are not associated with obesity in either children or adults (Holmberg and Thelin, 2013).

Milk is composed of a variety of compounds. Besides fat, other compounds can affect childhood obesity. Cow milk-based infant formula has been proposed to be a cause of increased prevalence of childhood obesity due to high activation of the mechanistic target of rapamycin complex 1 (mTORC1) pathway by leucine (Melnik, 2012). The high amount of protein present in cow milk compared with human milk has been associated with increased body mass index in children (Luque et al., 2016). However, a study conducted in Chile in 2008 found that consumption of milk compared with sweetened beverages over a 16 -wk period in children aged 8 to $10 \mathrm{yr}$ increased lean body mass and height (Albala et al., 2008). Similarly, a case study in Greece in children aged 7 to 15 yr found that children with obesity consumed significantly more sugar-sweetened bever- 
ages than children without obesity (Papandreou et al., 2013). Overall, it appears to be beneficial to consume dairy at a young age instead of sugar-sweetened drinks to help combat obesity and lower the risk of associated diseases later in life.

All of the above studies that investigated the link between dairy consumption and incidence of childhood obesity were observational. No studies have yet demonstrated a direct link between the two. It is important to understand whether milk plays a direct role in childhood obesity because the recommendations for parents working toward prevention are still conflicting. Conducting such studies requires the use of proper animal models. Pigs have previously been shown to be sufficient models for humans when looking at factors potentially causing obesity (Hanhineva et al., 2013).

Using growing piglets as our model for young children and by assessing overall weight gain, back fat thickness, and adipocyte formation, we sought to determine whether the oral consumption of milk could affect fat accumulation at an early age compared with piglets receiving a normal growing diet supplemented with a maltodextrin solution. We hypothesize that piglets receiving bovine milk daily will have lower amounts of back fat and the large adipocytes associated with hypertrophic growth.

\section{MATERIALS AND METHODS}

\section{Animals}

Experimental procedures used in this study were approved by the Institutional Animal Care and Use Committees of Oregon State University (protocol \#4691). Two studies were carried out between January and May 2016 (study 1) and 2017 (study 2).

Study 1 was run as a pilot study. Eight male Yorkshire piglets from 2 litters from the Oregon State University Swine Center, all 5 wk of age with starting weights ranging from 4.1 to $6.2 \mathrm{~kg}$, were randomly assigned to groups, blocking for weight and litter, for a 13-wk trial. In study 2, 12 Duroc-Berkshire male piglets, 8 to $9 \mathrm{wk}$ of age with a starting weight ranging from 12.9 to 18.7 $\mathrm{kg}$ from 4 litters, were purchased from a commercial operation and randomly assigned to groups, blocking for weight and litter for an 11-wk trial. The number of piglets used ( $\mathrm{n}=6$ per group) was based on the results from study 1 and a prior study that used pigs as a model for childhood obesity (Toedebusch et al., 2014). The piglets in study 1 were kept in the Swine Center in $6-\mathrm{m}^{2}$ pens with slatted floors and individual heat lamps. The piglets in study 2 were kept in the Hogg Animal Metabolism Barn in a temperature-controlled room in $1.3-\mathrm{m}^{2}$ pens with the ground lined with AstroTurf (Dalton, GA). All pigs had unlimited access to water and their pens were cleaned regularly.

In both trials, piglets were fed every morning between 0700 and $0800 \mathrm{~h}$; consumed and refused feed was weighed and recorded daily. On d 1, piglets were fed a Grolean Grower 50-140 diet (15.5\% CP; CHS Inc., Sioux Falls, SD) at an amount of approximately $7 \%$ of the average BW of the group. After $\mathrm{d} 1$, the amount fed was adjusted based on the amount of refused feed, such that if a piglet had $<100 \mathrm{~g}$ of refused feed that morning, the amount of feed was increased by $200 \mathrm{~g}$; if a piglet had $>100 \mathrm{~g}$ of refused feed, they were fed the same amount as the previous day; if a piglet had 2 or more consecutive days of $>100 \mathrm{~g}$ of refused feed, then the feed was decreased by $50 \mathrm{~g}$ for that day. In addition to the feed, the piglets received an isocaloric supplement of either a maltodextrin solution (cat. no. 007-345-0341, Honeyville, Rancho Cucamonga, CA) or whole cow milk. The milk was collected daily from the Oregon State University Dairy Center bulk tank and fed to the pigs within an hour of collection. The maltodextrin solution was made every 3 to $4 \mathrm{~d}$ and kept refrigerated when not being fed. For piglets in the milk group, $750 \mathrm{~mL}$ was fed daily (4.8\% fat, 3.6\% protein, $4.8 \%$ lactose), whereas piglets in the maltodextrin groups were fed $500 \mathrm{~mL}$ of solution daily. The amount of maltodextrin solution was calculated based on the number of calories in the milk ( $576.3 \mathrm{kcal}$ in 750 $\mathrm{mL}$ ), given that maltodextrin has an energy density of $4 \mathrm{kcal} / \mathrm{g}$. Each piglet received $144 \mathrm{~g}$ of maltodextrin mixed in $500 \mathrm{~mL}$ of water to make it a palatable consistency. In study 2, the supplements were fed in small troughs separate from their feed troughs, whereas in study 1, the supplements were mixed directly with food. Piglets in the second study were given their food after they drank their supplement, usually within 1 to 2 min. Piglets in the first study were euthanized in wk 13 of the study in the Oregon State University Clark Meat Laboratory using a captive bolt gun. Piglets in the second study were euthanized at the end of 11 wk via a jugular injection of pentobarbital (Somnasol Euthanasia, cat. no. EU-HS-045-100-0; Henry Schein, Melville, NY).

\section{Piglet Intake and Weight Data}

Daily feed intake was calculated as feed provided minus refusals for each individual piglet. At d 0 of the trial and each week after, the piglets were individually weighed. Average daily gain $(\mathrm{kg})$ was calculated by dividing the weight gained in 1 wk by $7 \mathrm{~d}$. Feed conversion ratio (FCR) was calculated by taking the average 
daily intake (ADI, $\mathrm{kg}$ ) for each week and dividing it by the ADG for the same week.

\section{Fat Thickness Measurements}

In vivo back fat measurements were taken via transcutaneous ultrasonography on the left side of the pig from $7 \mathrm{~cm}$ off the dorsal midline at the level of the head of the last rib on $\mathrm{d} 3,31,59$, and 71 of the trial. Ultrasonographic coupling gel was applied (Aquasonic 100 Ultrasound Transmission Gel, Parker Laboratories Inc., Fairfield, NJ) and a digital image was captured using a linear-array $5-\mathrm{MHz}$ probe (Mindray M5, Mindray North America, Mahwah, NJ). Ultrasound images were then analyzed using Image J $1.51 \mathrm{k}$ software (National Institutes for Health, Bethesda, MD). Briefly, the internal scale provided on the ultrasound image was used to establish a scale to give exact measurements of the thickness of the subcutaneous back fat.

Direct back fat measurements were taken immediately following euthanasia. In study 2, after euthanasia, photographs of the back subcutaneous fat were taken just below the last rib on the left of the animal and of the neck subcutaneous fat at approximately $15 \mathrm{~cm}$ caudal to the occipital bone and left of the midline, with a ruler in the picture for scale (Supplemental Figure S1; https://doi.org/10.3168/jds.2018-15201). The thickness of the subcutaneous fat was analyzed using ImageJ (National Institutes for Health). Briefly, the ruler in the picture was used to establish a scale to give exact measurements of the thickness of the subcutaneous back fat. In study 1, a ruler was used to directly measure the back fat (i.e., no photographs were taken) after euthanasia.

\section{Adipose Histology Data}

Subcutaneous adipose tissue samples were collected from the same area as the back fat images at euthanasia and placed in tubes with $10 \%$ buffered formalin (cat. no. CA71007-348, VWR, Radnor, PA). The samples were paraffin-embedded, sectioned, and stained with hematoxylin-eosin by the Oregon State University Veterinary Diagnostic Laboratory (Supplemental File S1; https://doi.org/10.3168/jds.2018-15201). Seven images per sample at $10 \times$ magnification were taken using an inverted robotic microscope (Leica DMI6000B, Leica Microsystems, Buffalo Grove, IL) and analyzed using Cell Profiler 3.0.0 (Carpenter Lab, Broad Institutes of Harvard and MIT, Cambridge, MA; cellprofiler.org) to obtain the area of adipocytes (Supplemental File S2, Cell Profiler pipeline file used to obtain area of adipocytes; https://doi.org/10.3168/jds.2018-15201).

\section{Statistical Analysis}

Data collected during the time course were analyzed using Proc GLIMMIX of SAS (version 9.4; SAS Institute Inc., Cary, NV) with treatment, time, and their interaction as main effects and pig as random. All the other data were analyzed by $\mathrm{R}$ (version 3.2 .3 ; https:// www.r-project.org/) using a linear mixed-effects model with treatment as the main effect and pig as the random variable. An ANOVA Type III with Satterthwaite approximation for degrees of freedom was run to calculate $P$-values; a $P$-value of $<0.05$ denotes a biological significant effect whereas $P$-values $>0.05$ and $<0.1$ denote a trend.

\section{RESULTS}

\section{Pig Intake and Weights}

In study 1 , the piglets fed milk supplement had a numerically greater ADG $(P=0.12)$ and a numerically lower FCR (i.e., greater efficiency in converting food to BW; $P=0.11$ ) compared with control piglets (Figure $1 \mathrm{AB})$. Average daily intake and BW were significantly affected by treatment $\times$ time $(P<0.05)$, with both being greater at the end of the study in the piglets fed milk (Figure 1D).

In study 2, the piglets fed milk did not show any significant differences in ADG, FCR, ADI, or BW compared with control (maltodextrin-supplemented) piglets (Figure 2).

\section{Back and Neck Fat Data}

In study 1, control piglets had lesser back fat and neck fat thickness compared with milk-fed piglets but no differences were detected in study 2 (Table 1 ). The thickness of the back fat measured by using an ultrasonographic probe throughout the studies did not differ significantly between control and milk-fed piglets in both studies (Figure 3).

\section{Adipose Histology Data}

In study 1, we detected a numerically lower average area of adipocytes in milk-fed compared with control piglets $(P=0.12$; Table 2$)$. The grouping of adipocytes based on the original distribution showed a bimodal distribution (Figure 4). Milk-treated piglets had a lower frequency of adipocytes with areas of 400 and $1,000 \mu \mathrm{m}^{2}(P<0.05)$ and a tendency $(P=0.09)$ for a greater frequency of adipocytes with area of $150 \mu \mathrm{m}^{2}$.

In study 2 , we detected no differences in the average area of adipocytes $(P=0.29$, Table 2$)$. Compared with 
control piglets, the back fat of milk-fed piglets had a significantly $(P<0.05)$ lower frequency of adipocytes with areas of 300,400 , and $500 \mu \mathrm{m}^{2}$ and a tendency $(P$ $=0.06$ ) for a greater frequency of adipocytes with an area of 2,000 $\mathrm{mm}^{2}$ (Figure 4). Compared with controls, the milk-fed pigs had a larger average in the $\geq 300$ $\mu \mathrm{m}^{2}$ adipocytes (663.8 vs. $\left.582.1 \mu^{2} ; P=0.018\right)$ but a smaller average in the $<300-\mu \mathrm{m}^{2}$ adipocytes (122.1 vs. $\left.125.3 \mu \mathrm{m}^{2} ; P=0.067\right)$.

\section{DISCUSSION}

In study 1 , feeding the milk supplement contributed to greater subcutaneous adipose tissue deposition in the back and neck area, meaning that milk could affect


fat deposition more than sugary drinks. The effect was inconsistent, however, because the same observations were not present in study 2 . This inconsistency can be attributed to various factors. The measurement of back fat after euthanasia was less precise in study 1 than in study 2 . The piglets in study 1 were from 2 litters and were purebred, whereas those in study 2 were from 4 crossbred litters, and thus had larger genetic variance, which is a more realistic human model (Harrill and McAllister, 2017). The piglets in study 1 were only 5 wk of age when enrolled; that is, directly after weaning. The piglets in study 2 were older and had been on solid food for 3 to $4 \mathrm{wk}$ before starting the study. Based on the amount of diarrhea recorded (Supplemental Table S1; https://doi.org/10.3168/jds.2018-15201), piglets in
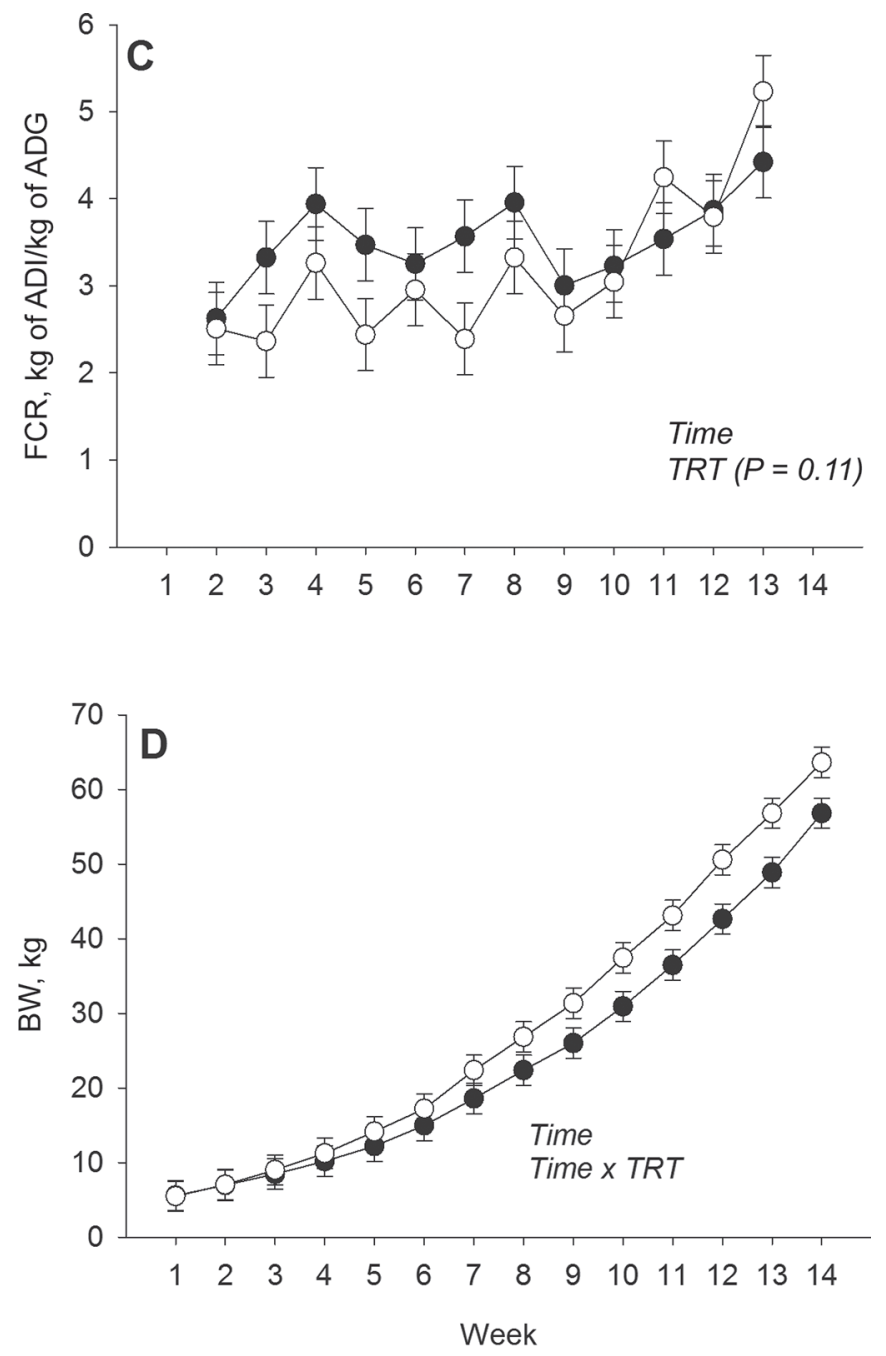

Figure 1. (A) Average daily gain; (B) average daily intake (ADI); (C) feed conversion ratio (FCR = ADI/ADG); and (D) weekly BW in piglets of study 1 supplemented with up to $750 \mathrm{~mL}$ of milk or an isocaloric amount of maltodextrin $(\mathrm{CTR})$. TRT $=$ overall effect of milk (treatment), Time $=$ overall effect of time; Time $\times$ TRT $=$ interaction between time and TRT. Significance and tendency of the effect is indicated by the $P$-value associated with the effect. Error bars represent SE. 
Table 1. Thickness of the adipose tissue in dorsal (back) and neck area of piglets supplemented with up to $750 \mathrm{~mL}$ of milk a day or an isocaloric amount of maltodextrin (control) (study $1, \mathrm{n}=4$ per group)

\begin{tabular}{|c|c|c|c|c|c|}
\hline \multirow[b]{2}{*}{ Study } & \multirow{2}{*}{$\begin{array}{l}\text { Fat } \\
\text { tissue }\end{array}$} & \multicolumn{2}{|c|}{ Treatment } & \multirow[b]{2}{*}{ SEM } & \multirow[b]{2}{*}{$P$-value } \\
\hline & & Control & Milk & & \\
\hline \multirow[t]{2}{*}{1} & Back & 1.71 & 2.35 & 0.19 & 0.04 \\
\hline & Neck & 2.60 & 3.11 & 0.16 & 0.04 \\
\hline \multirow[t]{2}{*}{2} & Back & 2.49 & 2.29 & 0.16 & 0.39 \\
\hline & Neck & 4.18 & 3.94 & 0.22 & 0.43 \\
\hline
\end{tabular}

study 1 had a difficult time adjusting to the treatments. They were also exposed to a wider range of temperatures than the piglets in study 2. Furthermore, in study 1 , mixing of the milk in the feed might have increased the consumption of feed compared with control piglets, whereas in study 2 , the separation of the milk from the feed might have removed such an effect.

Obesity can be associated with increased adipose tissue hyperplasia, hypertrophy, or both, depending on the extent of each (Landgraf et al., 2015). These processes will occur throughout an individual's lifetime, especially during childhood when the energy stored and required constantly changes (Avram et al., 2007). When one or both of these processes occur at a greater rate than the body needs that, the risk of obesity increases (Avram et al., 2007; Heinonen et al., 2014). The tendency of the milk-fed piglets in study 1 to have a higher frequency of the smaller adipocytes indicates greater adipogenesis and hyperplasia, which can explain, in part, the greater back fat thickness observed (Parlee et al., 2014). A


Figure 2. (A) Average daily gain; (B) average daily intake (ADI); (C) feed conversion ratio (FCR = ADI/ADG); and (D) weekly BW in piglets of study 2 supplemented with up to $750 \mathrm{~mL}$ of milk or an isocaloric amount of maltodextrin (CTR). Time $=$ overall significant effect of time. Significance and tendency of the effect is indicated by the $P$-value associated with the effect. Error bars represent SE. 


\section{Treatment $\square \mathrm{C} \square \mathrm{M}$}

\section{A}

Study 1

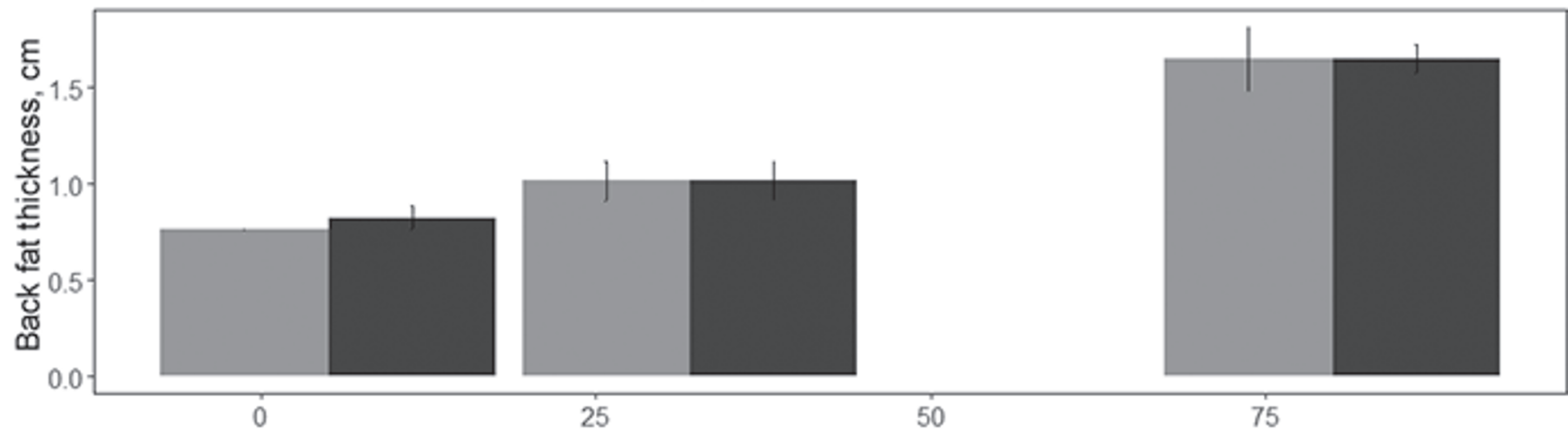

B

Study 2

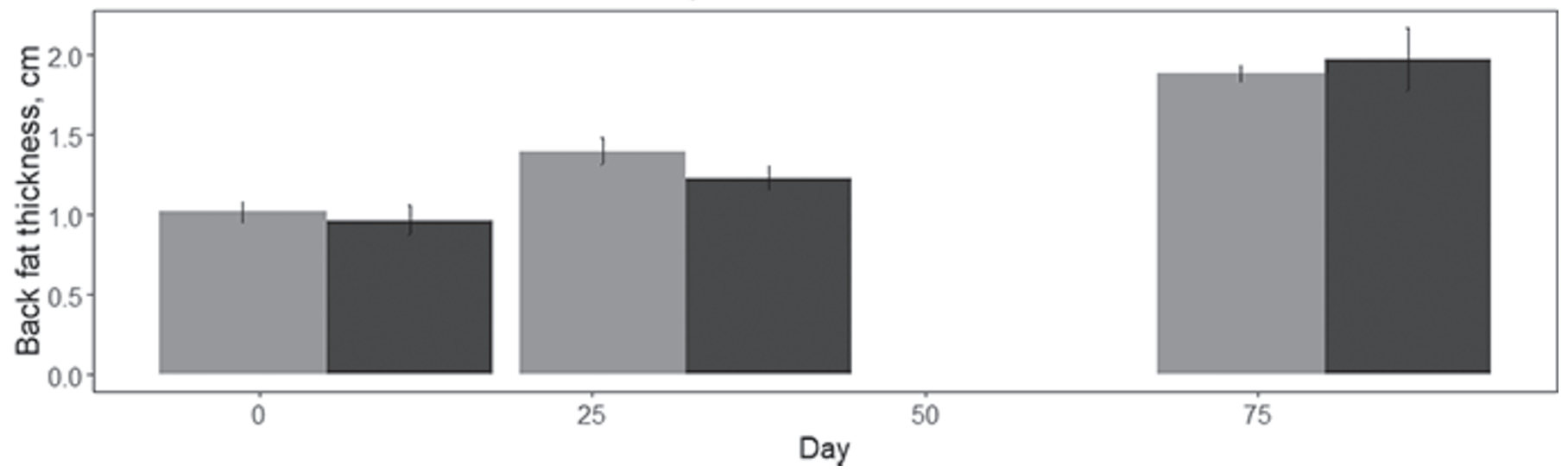

Figure 3. Back fat thickness (cm) measured using ultrasound in study 1 (A) and study 2 (B) in piglets supplemented with up to 750 mL of milk (M) or an isocaloric amount of maltodextrin (C). No significant effects were observed. Error bars represent SE.

greater frequency of some medium-sized or large adipocytes in the control piglets could indicate a decrease in adipogenesis and increased lipogenesis compared with milk-fed piglets in study 1. Larger adipocytes can be associated with insulin resistance (Parlee et al., 2014). Adipocyte hypertrophy-associated obesity has been linked to both insulin resistance and the onset of type 2 diabetes, along with lipotoxicity (Weyer et al., 2000;

Table 2. Mean area $\left(\mu \mathrm{m}^{2}\right)$ of adipocytes in the back fat of piglets supplemented with up to $750 \mathrm{~mL}$ of milk a day or an isocaloric amount of maltodextrin (control) (study $2, \mathrm{n}=6$ per group)

\begin{tabular}{|c|c|c|c|c|}
\hline \multirow[b]{2}{*}{ Study } & \multicolumn{2}{|c|}{ Treatment } & \multirow[b]{2}{*}{ SEM } & \multirow[b]{2}{*}{$P$-value } \\
\hline & Control & Milk & & \\
\hline 1 & 446.8 & 397.0 & 11.7 & 0.12 \\
\hline 2 & 370.9 & 398.0 & 9.85 & 0.29 \\
\hline
\end{tabular}

Virtue and Vidal-Puig, 2010; Gustafson et al., 2015; Landgraf et al., 2015; Jang et al., 2016). In study 2, the distribution of adipocyte sizes was, to some extent, opposite that of study 1 , suggesting that milk-fed piglets had more active lipogenesis and a tendency for a large amount of adipogenesis compared with control piglets. The results from both studies indicate an inconsistent effect of milk on adipogenesis and lipogenesis but, overall, indicate that milk had a tendency to increase adipogenesis.

Hypertrophic adipose tissue can lead to higher incidences of insulin resistance, liver fat, and inflammation (Heinonen et al., 2014). This association is due to the limited expandability of subcutaneous white adipose tissue along with cell signaling from hypertrophic adipocytes (Virtue and Vidal-Puig, 2010; Gustafson et al., 2015; Landgraf et al., 2015). Preadipocyte commitment and adipogenesis are often impaired under such 

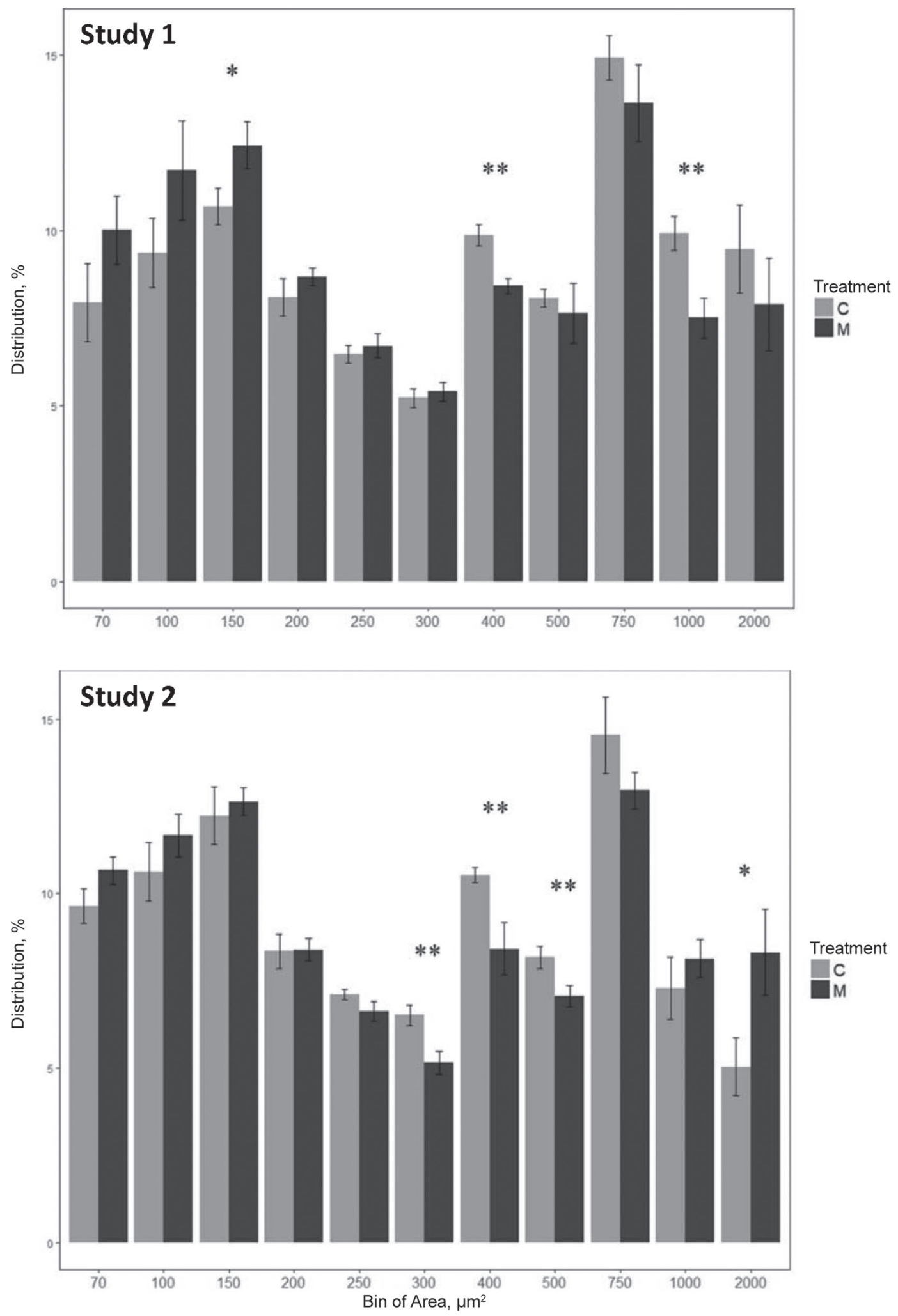

Figure 4. Area size distribution of adipocytes $\left(\mu \mathrm{m}^{2}\right)$ collected from the back fat of piglets supplemented with up to $750 \mathrm{~mL}$ of milk $(\mathrm{M})$ or an isocaloric amount of maltodextrin $(\mathrm{C})$ for $13 \mathrm{wk}$ (study 1 ) or 11 wk (study 2). Statistical difference between the piglets in $\mathrm{M}$ and $\mathrm{C}$ : $* * P<$ 0.05 or $* P<0.10$ (tendency). Error bars represent SE. 
conditions, contributing to an increase in metabolic dysregulation (Virtue and Vidal-Puig, 2010; Cawthorn et al., 2012; Gustafson et al., 2015). An increase in adipogenesis can help balance out the rate of growth of hypertrophic adipocytes, and smaller adipocytes have greater insulin sensitivity, reducing the risk of developing obesity and insulin resistance, and leading to type 2 diabetes (Roberts et al., 2009; Virtue and Vidal-Puig, 2010). Therefore, our data indicate that milk might help prevent type 2 diabetes in children or, as a longterm effect, in adults, as noted in several studies but not in all (Soedamah-Muthu et al., 2013).

Many components of milk could play a role in obesity. As previously mentioned, the high concentration of saturated fat in milk has been a cause for concern, although many studies have found a negative correlation between dairy fat intake and body mass index (Huh et al., 2010; Vanderhout et al., 2016; Beck et al., 2017). Milk is also known to be high in calcium, which has been linked to weight loss and maintenance, as well as with a decreased incidence of hypertension (Elwood et al., 2010; Villarroel et al., 2014). Milk is rich in protein, specifically whey protein, that has been shown to increase secretion of insulin and might help lower the risk of developing type 2 diabetes (McGregor and Poppitt, 2013).

Adipocytes are produced via resident mesenchymal stem cells upon activation of several transcription factors, chiefly peroxisome proliferator-activated receptor (PPAR) $\gamma$ (Sarjeant and Stephens, 2012). Among others, PPAR $\gamma$ can be activated by the mTORC1 pathway, leading to increased adipogenesis and insulin sensitivity (Kim and Chen, 2004; Blanchard et al., 2012; Marion-Letellier et al., 2016). The branched-chain AA, specifically leucine, rich in the whey protein in milk, can directly stimulate mTORC1 (Melnik et al., 2013). Besides adipogenesis, the mTORC1 pathway can increase lipogenesis via sterol response element binding protein-1 (SREBP-1; Melnik et al., 2013). Thus, milk, via the mTORC1-PPAR $\gamma$-SREBP-1 axis, could affect differentiation of mesenchymal stem cells and, in turn, affect adipogenesis and lipogenesis. In addition to its role in adipogenesis, PPAR $\gamma$ can increase the production of adiponectin by mature adipocytes (El Sayyad et al., 2016). Adiponectin is associated with an increase in insulin sensitivity and an increase in lipolysis (Virtue and Vidal-Puig, 2010). The tendency for an increase in adipogenesis observed in the milk-supplemented piglets in both studies could be due to an increase in expression of PPAR $\gamma$, which would in turn increase the production of adiponectin. This would mean that the milk-supplemented piglets would be less likely to develop insulin resistance and type 2 diabetes.

\section{Limitations}

In our studies, the piglets could not be considered obese because they reached a BW that is typical for the species ( $\sim 90 \mathrm{~kg}$ at $20 \mathrm{wk}$ of age). The present studies lasted $\leq 13 \mathrm{wk}$, with the piglets being euthanized at approximately $20 \mathrm{wk}$ of age. Although detrimental effects of obesity in children can be seen at an early age, such as earlier puberty in girls and later puberty in boys, the major health problems associated with obesity are observed in young and older adults (Cali and Caprio, 2008; Burt Solorzano and McCartney, 2010). Another limitation of our study was the small number of animals used to capture differences. Therefore, a long-term study that followed the piglets until later in life (i.e., 2 yr old) and used a larger number of animals is necessary to demonstrate a direct effect of milk on obesity and associated diseases.

\section{CONCLUSIONS}

Taking into account the issues of a lack of genetic variation and young age of the piglets associated with the first study and the above limitations, we conclude that supplementing milk at an early age does not have an effect on weight gain in growing piglets, although the effect on overall fat accumulation was inconsistent. Thus, our studies suggest that children consuming milk are not more or less likely to become obese. However, the observed effect on adipogenesis and lipogenesis is of interest. These data point to a likely effect of milk on the preadipocytes or the mesenchymal stem cells that give rise to the adipocytes. If milk does affect mesenchymal stem cells, this could have long-term implications. Therefore, it appears logical to investigate the effect of milk on mesenchymal stem cells.

\section{ACKNOWLEDGMENTS}

KS carried out the experiments, collected, analyzed, and interpreted the data, performed the literature search, generated the figures, and wrote the manuscript; MB conceived the experiments, interpreted the data, and wrote the manuscript; MK conceived the experiments and collected ultrasonographic data. All authors were involved in writing the paper and had final approval of the submitted and published versions. The study was supported by the USDA National Institute of Food and Agriculture (Washington, DC) Agriculture and Food Research Initiative Exploratory grant (project\# ORE00130) along with the National Needs Graduate Fellowships, Grant \#2014-38420-21800. The authors thank Brandon Batty for the analysis of 
the ultrasound data using ImageJ. The authors also thank Matthew Kennedy and his crew for assistance in procuring the piglets and setting up and cleaning the pens, and Sarah Akers, Cassie Penix, Emily Sahagun, Randi Wilson, Tamay Guevara, Minda Newhouse, Katie White, Eric Tam, Catalina Tello, Enrique Perez, Kaitlyn Vander Pas, Nina Enos, Brandon Batty, Emilie Peterson, Nicolas Rivero, Winnie Luo, and Sebastiano Busato for their help with feeding the piglets and collecting samples.

\section{REFERENCES}

Albala, C., C. B. Ebbeling, M. Cifuentes, L. Lera, N. Bustos, and D. S. Ludwig. 2008. Effects of replacing the habitual consumption of sugar-sweetened beverages with milk in Chilean children. Am. J. Clin. Nutr. 88:605-611.

Avram, M. M., A. S. Avram, and W. D. James. 2007. Subcutaneous fat in normal and diseased states. J. Am. Acad. Dermatol. 56:472-492. https://doi.org/10.1016/j.jaad.2006.06.022.

Beck, A. L., M. Heyman, C. Chao, and J. Wojcicki. 2017. Full fat milk consumption protects against severe childhood obesity in Latinos. Prev. Med. Rep. 8:1-5. https://doi.org/10.1016/j.pmedr.2017.07 .005 .

Blanchard, P.-G., W. T. Festuccia, V. P. Houde, P. St-Pierre, S. Brûlé, V. Turcotte, M. Côté, K. Bellmann, A. Marette, and Y. Deshaies. 2012. Major involvement of mTOR in the PPAR $\gamma$-induced stimulation of adipose tissue lipid uptake and fat accretion. J. Lipid Res. $53: 1117-1125$.

Burt Solorzano, C. M., and C. R. McCartney. 2010. Obesity and the pubertal transition in girls and boys. Reproduction 140:399-410. https://doi.org/10.1530/REP-10-0119.

Cali, A. M. G., and S. Caprio. 2008. Obesity in children and adolescents. J. Clin. Endocrinol. Metab. 93:S31-S36. https://doi.org/10 $.1210 /$ jc. $2008-1363$.

Cawthorn, W. P., E. L. Scheller, and O. A. MacDougald. 2012. Adipose tissue stem cells meet preadipocyte commitment: Going back to the future. J. Lipid Res. 53:227-246. https://doi.org/10.1194/ jlr.R021089.

Cheung, P. C., S. A. Cunningham, K. M. V. Narayan, and M. R. Kramer. 2016. Childhood obesity incidence in the United States: A systematic review. Child. Obes. 12:1-11. https://doi.org/10.1089/ chi.2015.0055.

Daniels, S. R., and F. R. Greer. 2008. Lipid screening and cardiovascular health in childhood. Pediatrics 122:198-208. https://doi.org/ 10.1542/peds.2008-1349.

El Sayyad, H. I. H., M. A. Sobh, S. A. Khalif, and O. K. R. El-Sayyad. 2016. Adipose derived mesenchymal stem cell differentiation into adipogenic and osteogenic stem cells. Glob. J. Stem. Cell. Biol. Transplant. 2:017-024.

Elwood, P. C., J. E. Pickering, D. I. Givens, and J. E. Gallacher. 2010. The consumption of milk and dairy foods and the incidence of vascular disease and diabetes: An overview of the evidence. Lipids 45:925-939. https://doi.org/10.1007/s11745-010-3412-5.

Gustafson, B., S. Hedjazifar, S. Gogg, A. Hammarstedt, and U. Smith. 2015. Insulin resistance and impaired adipogenesis. Trends Endocrinol. Metab. 26:193-200. https://doi.org/10.1016/j.tem.2015 .01 .006 .

Hanhineva, K., T. Barri, M. Kolehmainen, J. Pekkinen, J. Pihlajamäki, A. Vesterbacka, G. Solano-Aguilar, H. Mykkänen, L. O. Dragsted, J. F. Urban, and K. Poutanen. 2013. Comparative nontargeted profiling of metabolic changes in tissues and biofluids in high-fat diet-fed Ossabaw pig. J. Proteome Res. 12:3980-3992. https://doi.org/10.1021/pr400257d.

Harrill, A. H., and K. A. McAllister. 2017. New rodent population models may inform human health risk assessment and identifica- tion of genetic susceptibility to environmental exposures. Environ. Health Perspect. 125:086002. https://doi.org/10.1289/EHP1274.

Heinonen, S., L. Saarinen, J. Naukkarinen, A. Rodríguez, G. Frühbeck, A. Hakkarainen, J. Lundbom, N. Lundbom, K. Vuolteenaho, E. Moilanen, P. Arner, S. Hautaniemi, A. Suomalainen, J. Kaprio, A. Rissanen, and K. H. Pietiläinen. 2014. Adipocyte morphology and implications for metabolic derangements in acquired obesity. Int. J. Obes. (Lond.) 38:1423-1431. https://doi.org/10.1038/ijo.2014 .31 .

Holmberg, S., and A. Thelin. 2013. High dairy fat intake related to less central obesity: A male cohort study with 12 years' follow-up. Scand. J. Prim. Health Care 31:89-94. https://doi.org/10.3109/ 02813432.2012.757070.

Huh, S. Y., S. L. Rifas-Shiman, J. W. Rich-Edwards, E. M. Taveras, and M. W. Gillman. 2010. Prospective association between milk intake and adiposity in preschool-aged children. J. Am. Diet. Assoc. 110:563-570. https://doi.org/10.1016/j.jada.2009.12.025.

Jang, H., M. Kim, S. Lee, J. Kim, D.-C. Woo, K. W. Kim, K. Song, and I. Lee. 2016. Adipose tissue hyperplasia with enhanced adipocyte-derived stem cell activity in Tc1(C8orf 4)-deleted mice. Sci. Rep. 6:35884. https://doi.org/10.1038/srep35884.

Kim, J., I. Lee, and S. Lim. 2017. Overweight or obesity in children aged 0 to 6 and the risk of adult metabolic syndrome: A systematic review and meta-analysis. J. Clin. Nurs. 26:3869-3880. https://doi .org/10.1111/jocn.13802.

Kim, J. E., and J. Chen. 2004. Regulation of peroxisome proliferatoractivated receptor- $\gamma$ activity by mammalian target of rapamycin and amino acids in adipogenesis. Diabetes 53:2748-2756.

Kratz, M., T. Baars, and S. Guyenet. 2013. The relationship between high-fat dairy consumption and obesity, cardiovascular, and metabolic disease. Eur. J. Nutr. 52:1-24. https://doi.org/10.1007/ s00394-012-0418-1.

Lakshman, R., C. E. Elks, and K. K. Ong. 2012. Childhood obesity. Circulation 126:1770-1779. https://doi.org/10.1161/ CIRCULATIONAHA.111.047738.

Landgraf, K., D. Rockstroh. I. V. Wagner, S. Weise, R. Tauscher, J. T. Schwartze, D. Löffler, U. Bühligen, M. Wojan, H. Till, J. Kratzsch, W. Kiess, M. Blüher, and A. Körner. 2015. Evidence of early alterations in adipose tissue biology and function and its association with obesity-related inflammation and insulin resistance in children. Diabetes 64:1249-1261. https://doi.org/10.2337/db14-0744.

Ludwig, D. S., and W. C. Willett. 2013. Three daily servings of reduced-fat milk: An evidence-based recommendation? JAMA Pediatr. 167:788. https://doi.org/10.1001/jamapediatrics.2013.2408.

Luque, V., R. Closa-Monasterolo, J. Escribano, and N. Ferré. 2016. Early programming by protein intake: the effect of protein on adiposity development and the growth and functionality of vital organs. Nutr. Metab. Insights 8:49-56. https://doi.org/10.4137/ NMI.S29525.

Marion-Letellier, R., G. Savoye, and S. Ghosh. 2016. Fatty acids, eicosanoids and PPAR gamma. Eur. J. Pharmacol. 785:44-49. https:/ /doi.org/10.1016/j.ejphar.2015.11.004.

McGregor, R. A., and S. D. Poppitt. 2013. Milk protein for improved metabolic health: A review of the evidence. Nutr. Metab. (Lond.) 10:46. https://doi.org/10.1186/1743-7075-10-46.

Melnik, B. C. 2012. Excessive leucine-mTORC1-signalling of cow milk-based infant formula: The missing link to understand early childhood obesity. J. Obes. 2012:197653. https://doi.org/10.1155/ 2012/197653.

Melnik, B. C., S. M. John, and G. Schmitz. 2013. Milk is not just food but most likely a genetic transfection system activating mTORC1 signaling for postnatal growth. Nutr. J. 12:103.

Ogden, C. L., M. D. Carroll, C. D. Fryar, and K. M. Flegal. 2015. Prevalence of obesity among adults and youth: United States, 2011-2014. US Department of Health and Human Services, Centers for Disease Control and Prevention, National Center for Health Statistics. Accessed Jan. 28, 2018. https://www.cdc.gov/ nchs/products/databriefs/db219.htm.

Papandreou, D., E. Andreou, A. Heraclides, and I. Rousso. 2013. Is beverage intake related to overweight and obesity in school children? Hippokratia 17:42-46. 
Papoutsi, G. S., A. C. Drichoutis, and R. M. Nayga. 2013. The causes of childhood obesity: A survey. J. Econ. Surv. 27:743-767. https:/ /doi.org/10.1111/j.1467-6419.2011.00717.x.

Parlee, S. D., S. I. Lentz, H. Mori, and O. A. MacDougald. 2014. Quantifying size and number of adipocytes in adipose tissue. Methods Enzymol. 537:93-122. https://doi.org/10.1016/B978-0 -12-411619-1.00006-9.

Roberts, R., L. Hodson, A. L. Dennis, M. J. Neville, S. M. Humphreys, K. E. Harnden, K. J. Micklem, and K. N. Frayn. 2009. Markers of de novo lipogenesis in adipose tissue: Associations with small adipocytes and insulin sensitivity in humans. Diabetologia 52:882890. https://doi.org/10.1007/s00125-009-1300-4.

Sarjeant, K., and J. M. Stephens. 2012. Adipogenesis. Cold Spring Harb. Perspect. Biol. 4. https://doi.org/10.1101/cshperspect .a008417.

Soedamah-Muthu, S. S., G. Masset, L. Verberne, J. M. Geleijnse, and E. J. Brunner. 2013. Consumption of dairy products and associations with incident diabetes, CHD and mortality in the Whitehall II study. Br. J. Nutr. 109:718-726. https://doi.org/10.1017/ S0007114512001845.

Toedebusch, R. G., M. D. Roberts, K. D. Wells, J. M. Company, K. M. Kanosky, J. Padilla, N. T. Jenkins, J. W. Perfield, J. A. Ibdah, F. W. Booth, and R. S. Rector. 2014. Unique transcriptomic signature of omental adipose tissue in Ossabaw swine: A model of childhood obesity. Physiol. Genomics 46:362-375.
Vanderhout, S. M., C. S. Birken, P. C. Parkin, G. Lebovic, Y. Chen, D. L. O. Connor, and J. L. Maguire. 2016. Relation between milkfat percentage, vitamin $\mathrm{D}$, and $\mathrm{BMI} \mathrm{z}$ score in early childhood. Am. J. Clin. Nutr. 104:1657-1664. https://doi.org/10.3945/ajcn .116 .139675 .

Villarroel, P., E. Villalobos, M. Reyes, and M. Cifuentes. 2014. Calcium, obesity, and the role of the calcium-sensing receptor. Nutr. Rev. 72:627-637.

Virtue, S., and A. Vidal-Puig. 2010. Adipose tissue expandability, lipotoxicity and the metabolic syndrome-An allostatic perspective. Biochim. Biophys. Acta 1801:338-349. https://doi.org/10.1016/j .bbalip.2009.12.006.

Weyer, C., J. E. Foley, C. Bogardus, P. A. Tataranni, and R. E. Pratley. 2000. Enlarged subcutaneous abdominal adipocyte size, but not obesity itself, predicts type II diabetes independent of insulin resistance. Diabetologia 43:1498-1506.

Xu, S., and Y. Xue. 2016. Pediatric obesity: Causes, symptoms, prevention and treatment. Exp. Ther. Med. 11:15-20. https://doi .org/10.3892/etm.2015.2853.

Zemel, M. B. 2005. The role of dairy foods in weight management. J Am. Coll. Nutr. 24:537S-546S. https://doi.org/10.1080/07315724 .2005.10719502. 